\title{
Clinical Aspects of Acute Lung Insufficiency (ALI/TRALI)
}

\author{
Matthias Hecker Hans-Dieter Walmrath Werner Seeger Konstantin Mayer \\ University of Gießen Lung Center (UGLC), Gießen, Germany
}

\section{Key Words}

ARDS · Ventilation · Endothelium · PMN

\section{Summary}

Acute respiratory distress syndrome (ARDS) is a common clinical disorder caused by a variety of direct and indirect injuries to the lung, characterized by alveolar epithelial and endothelial injury resulting in damage to the pulmonary alveolar-capillary barrier. The cardinal clinical feature of ARDS, refractory arterial hypoxemia, is the result of protein-rich alveolar edema with impaired surfactant function, due to vascular leakage and vascular dysfunction with consequently impaired matching of ventilation to perfusion. Since its first description in 1967, considerable knowledge concerning the pathogenesis of ARDS has been obtained, however, a plethora of questions remain. Better understanding of the pathophysiology of ARDS has lead to the development of novel therapies, pharmacological strategies, and advances in mechanical ventilation. However, lung-protective ventilation is the only confirmed option in ARDS management improving survival, and few other therapies have translated into improved oxygenation or reduced ventilation time. But despite improvement in our understanding of the therapy and supportive care for patients with ARDS, mortality remains high. It is the purpose of this article to provide an overview of the definition, clinical features, and pathogenesis of ARDS, and to present and discuss therapeutic options currently available in order to effectively treat this severe disorder.

\author{
Schlüsselwörter \\ ARDS · Beatmung · Endothel · PMN
}

\section{Zusammenfassung}

Das akute Lungenversagen ("acute respiratory distress syndrome», ARDS) ist eine weit verbreitete Erkrankung, die durch eine Vielzahl unterschiedlicher pulmonaler und extrapulmonaler Ursachen ausgelöst werden kann und pathophysiologisch durch eine Schädigung der alveolärkapillären Barriere charakterisiert ist. Klinisches Kardinalsymptom, die refraktäre arterielle Hypoxämie, ist Resultat der Ausbildung eines eiweißreichen Lungenödems, das aufgrund einer gesteigerten Permeabilität, verursacht durch die Schädigung der alveolär-kapillären Integrität, entsteht. Seit der Erstbeschreibung des Syndroms konnte enormer Fortschritt im Verständnis der Pathogenese erzielt werden, wobei jedoch eine Vielzahl pathophysiologischer Fragen in Zukunft weiter untersucht werden muss. Ein besseres Verständnis der Pathophysiologie des akuten Lungenversagens, die Entwicklung neuer Therapieoptionen und Fortschritte im Bereich der Intensiv- und Beatmungsmedizin haben die Prognose dieser Erkrankung deutlich verbessert. Trotz intensiver Entwicklung und Forschung ist jedoch nur für die lungenprotektive Beatmung ein erhöhtes Überleben von ARDS-Patienten bewiesen. Nur wenige weitere Therapieansätzte zeigen verbesserte Oxygenierung oder eine Reduktion der Beatmungszeit. Aber trotz aller Fortschritte bleibt die Mortalität des akuten Lungenversagens sehr hoch. Ziel dieses Artikels ist es, einen Überblick über die Definition, klinische Charakteristika und Pathogenese des akuten Lungenversagens zu geben und die gegenwärtigen Therapieoptionen in der Behandlung des ARDS vorzustellen und kritisch zu diskutieren.

\begin{tabular}{ll}
\hline KARGER & $\oplus$ 2008 S. Karger GmbH, Freiburg \\
Fax +497614520714 & Accessible online at: \\
$\begin{array}{l}\text { E-mail Information@Karger.de } \\
\text { www.karger.com }\end{array}$ & www.karger.com/tmh
\end{tabular}




\section{Definition and Diagnosis}

The acute respiratory distress syndrome (ARDS) is a common clinical disorder characterized by alveolar epithelial and endothelial injury leading to the development of a protein-rich non-cardiogenic pulmonary edema and finally acute respiratory failure. The term ARDS was initially introduced by Ashbaugh et al. [1] in 1967 describing a clinical syndrome of acute respiratory distress and cyanosis refractory to oxygen therapy in 12 patients who required positive-pressure mechanical ventilation. Although this publication represented a landmark in formally defining the syndrome, the criteria lacked specificity leading to varying interpretations, making the comparison of results across clinical studies difficult and even impossible.

In 1994, the American-European Consensus Conference (AECC) proposed a revised definition for ARDS [2] which was now recognized as only the extreme manifestation of acute lung injury (ALI): ALI and ARDS are defined as syndromes of inflammation and increased pulmonary permeability associated with clinical, physiological, and radiological abnormalities (table 1). They are acute in onset, characterized by refractory hypoxemia, and associated with diffuse bilateral radiological lung field infiltrates. Chest radiographs reveal a progression from diffuse interstitial infiltrates to diffuse, fluffy, alveolar opacities. In contrast to the radiological features of a cardiogenic pulmonary edema, chest radiographs of ARDS patients often lack cardiomegaly, pleural effusions, and vascular redistribution. In the initial stage of ARDS, computed tomographic scanning reveals bilateral opacities which are more dense and pronounced predominantly in the dependent, posterior lung zones, whereas the anterior lung fields may be spared. The clinical and physiological severity of the pulmonary injury is distinguished by pulmonary gas exchange which is defined by the ratio of partial arterial pressure of oxygen $\left(\mathrm{PaO}_{2}\right)$ to the inspired fraction of oxygen $\left(\mathrm{FiO}_{2}\right)$. The term ALI refers to patients with $\mathrm{PaO}_{2} / \mathrm{FiO}_{2}$ ratio of $<300 \mathrm{mmHg}$, whereas a ratio of $<200 \mathrm{mmHg}$ defines ARDS regardless of the amount of positive end-expiratory pressure (PEEP) required to support sufficient oxygenation. To exclude a cardiogenic pulmonary edema, the pulmonary artery occlusion pressure (PAOP) should be $<18 \mathrm{mmHg}$, or no clinical evidence of left atrial hypertension as a sign of left heart failure should be detectable. Furthermore, the consensus definition recognizes the clinical symptoms without attention to specific molecular, immune, or physical events as a cause of respiratory failure, and is thus regarded as the clinical expression of a group of various processes causing diffuse alveolar damage.

Both ALI and ARDS may occur as a consequence of 2 distinct pathogenic events converging on a common pathophysiological pathway: a direct ('pulmonary') injury, affecting lung parenchyma such as pneumonia, aspiration, pulmonary contusion, or toxic inhalation, and an indirect ('extrapulmonary') insult (table 2). A principal example of an indirect mechanism is the sepsis syndrome which is regarded as the most prevalent
Table 1. Simplified consensus definition of ALI/ARDS [2]

\section{Acute onset}

Severe hypoxemia $\left(\mathrm{PaO}_{2} / \mathrm{FiO}_{2}\right.$ ratio of $<300 \mathrm{mmHg}$ for ALI, $<200 \mathrm{mmHg}$ for ARDS)

Diffuse bilateral pulmonary infiltrates on chest radiographs

Absence of left atrial hypertension (pulmonary-artery wedge pressure $<18 \mathrm{mmHg}$ )

Table 2. Major causes of ALI/ARDS

and lethal cause of ARDS, but also hypertransfusions of blood products, acute pancreatitis, non-thoracic trauma with shock, disseminated intravascular coagulation (DIC), and drug overdose (opiates, thiazides, paraquat) are widespread causes of an extrapulmonary lung injury [3]. All these incidents, either direct or indirect, might trigger ALI/ARDS resulting in a uniform pathological pattern in the late stage of the disease, but the precise pathophysiological mechanism in the early ARDS may vary according to the type of pulmonary injury occurring.

\section{Prevalence and Outcome}

The incidence of ALI and ARDS is difficult to estimate, and recent data range from 10 to 58 per 100,000 persons, with higher incidence rates in the United States [4-9]. According to recent data from a prospective European multi-center twomonth inception cohort study in 6,522 patients, the incidence of an ALI or ARDS was $7.1 \%$ of all patients admitted to an intensive care unit (ICU) [10]. It increases to $12.5 \%$ when considering only patients treated longer than $24 \mathrm{~h}$ in the ICU. A second study reported the incidence of ALI to be $4.5 \%$ of all ventilated patients on admission to the ICU [11].

The mortality rate associated with ARDS and ALI has declined from $50-70 \% 2$ decades ago to $30-40 \%$ at present in recent randomized trials [12]. The multiple organ failure syndrome is the major cause of death in ARDS. For most ARDS patients, the clinical outcome and prognosis is determined in the first 7-10 days after diagnosis, since within this period, half 

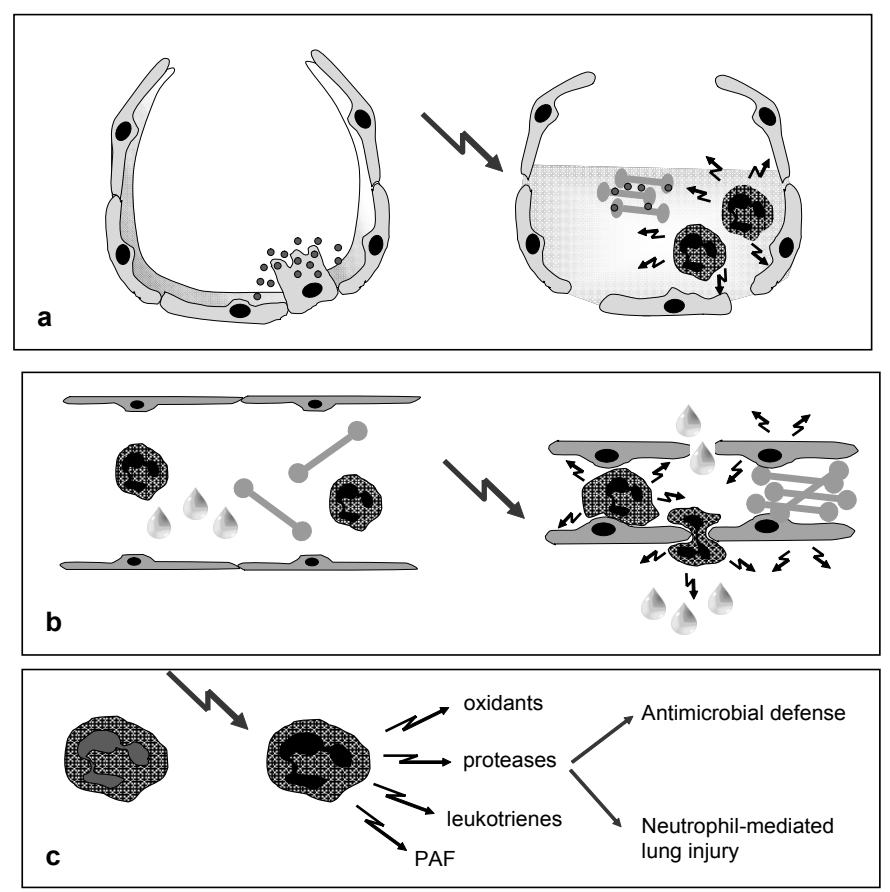

Fig. 1. Injury of epithelial cells, endothelial cells, and activation of neutrophils in ARDS. a Due to injury, a loss of surfactant-producing type II epithelial cells occurs. b Together with alveolar flooding, inactivation of surfactant by proteins, and recruitment of activated neutrophils, the capacity of gas exchange is seriously endangered. The recruitment of leukocytes into the alveolar space is due to local or systemic activation of endothelial cells and neutrophils. c Injury of endothelial cells is both cause and consequence of the pathophysiologic events. The activated neutrophils carry the capacity to both anti-microbial defence and self-destructive injury.

of the patients have died or have been weaned off mechanical ventilation [13]. Survivors of ARDS tend to be young trauma patients - their lung function generally recovers over 6-12 months but residual abnormalities, including mild restriction/obstruction, impaired gas exchange during exercise, or lowered diffusion capacity, often remain. Several prospective trials using the AECC criteria have identified predictors of poor clinical outcome. Prognostic indicators for increased mortality include advanced age, the presence of non-pulmonary organ dysfunction, liver cirrhosis, active malignancy, and septic shock; whereas the initial degree of gas exchange impairment is a poor predictor of the clinical outcome unless oxygenation disturbances remain severe and persist $\left(\mathrm{PaO}_{2} /\right.$ $\mathrm{FiO}_{2}<50$ for several days).

As lung injury can be caused by various mechanisms, several studies have focused on the identification of possible risk factors for the development of ALI/ARDS in order to prevent the incidence or progression of lung injury in high-risk populations. Hudson et al. [14] could demonstrate that patients with sepsis syndrome had the highest risk of developing ARDS (41\%), followed by multiple transfusions (36\%, defined as $>10$ red blood cell units within $12 \mathrm{~h}$ ), aspiration pneu- monia (22\%), and pulmonary contusion (22\%). Interestingly, another study demonstrated that bacteremia, defined as 2 positive blood cultures, is associated with a $3.8 \%$ risk of ARDS [15]. In summary, most epidemiological data currently available indicate that approximately $20-40 \%$ of patients with well-established risk factors develop ARDS with an increasing individual likelihood the more risk factors are present.

\section{Pathogenesis}

The alveolar-capillary barrier is formed by 2 distinct histological entities: the microvascular endothelium and the alveolar epithelium. The acute phase of ARDS is characterized by widespread disruption of this alveolar-capillary barrier, leading to increased permeability and thus the influx of proteinrich edema fluid into the lung, and accompanying cellular infiltrates (fig. 1). Another important consequence of lung edema formation is a pronounced reduction of lung compliance which, in concert with capillary obliteration and hypoxemic and inflammation-induced vasoconstriction, culminates in the development of increased pulmonary artery pressure with subsequent right heart dysfunction and hypoxemic, hypercarbic respiratory failure if left untreated. In parallel with this scenario, a significant ventilation-perfusion mismatch develops composed of intrapulmonary shunting and dead space ventilation resulting in further deterioration of oxygenation. In the following, several different mechanisms and locations of injury are presented, all to a certain extent implicated in the pathogenesis of ARDS-associated lung injury.

\section{Epithelial Injury}

After a direct ('pulmonary') insult which can be also induced experimentally, for example, by endotoxin inhalation or acid aspiration, the primary target of injury is the pulmonary epithelium. The degree of alveolar epithelial damage is regarded as a crucial predictor of clinical outcome. The healthy alveolar epithelium consists of flat type I cells forming the vast majority of the alveolar surface, and cuboidal type II cells, which play an essential role in surfactant production, ion transport, and proliferation/ differentiation into type I cells. In the case of ARDS, a lesion of the alveolar epithelium with subsequent loss of epithelial integrity and the disruption of type II cell in particular leads to i) impaired removal of fluid from the alveolar space resulting in lung edema formation, ii) a reduced production and turnover of surfactant due to injury of type II cells (contributing to the clinical course of worsening atelectasis and gas exchange), iii) an increased risk of septic shock in patients with bacterial pneumonia, and iv) in cases of severe epithelial damage, pulmonary fibrosis as a result of disorganized or insufficient pulmonary repair [16]. Furthermore, an injured epithelium may induce inflammatory activation of adjacent endothelium and recruit leukocytes from the vascular to the alveolar space. 

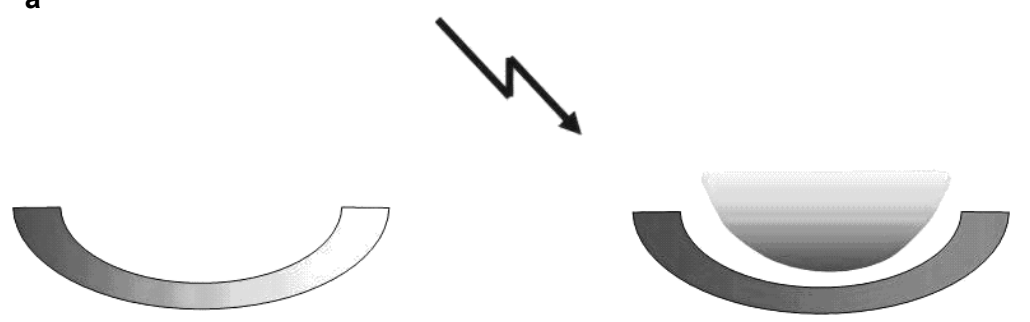

b
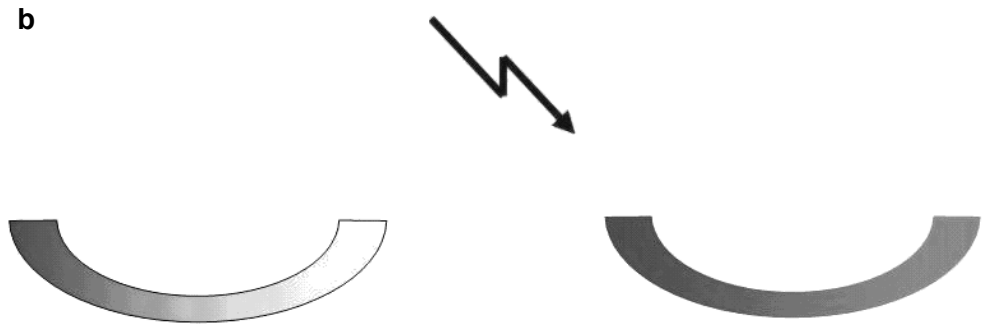

c

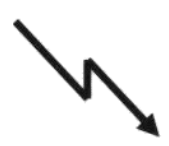

Fig. 2. Impact of ARDS on gas exchange. a ALI results in a combination of alveolar flooding, $\mathbf{b}$ formation of atelectasis, and activation of coagulation all resulting in a reduced capacity of gas exchange. c Together with a failure of ventilation-perfusion matching, severe hypoxemia ensues.
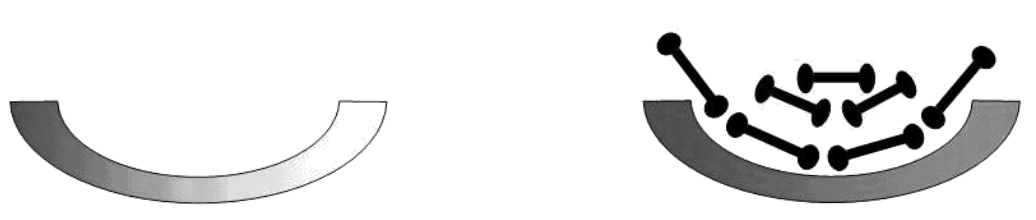

d
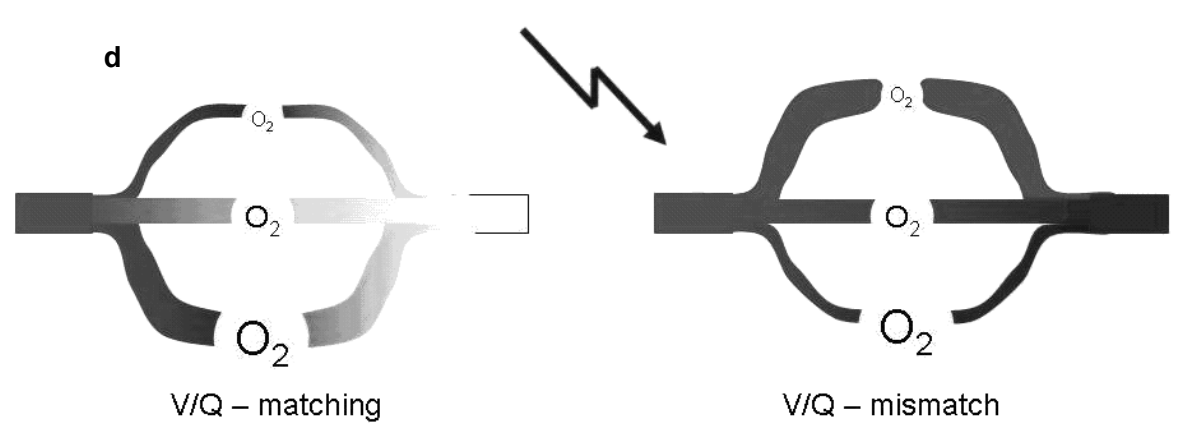

\section{Endothelial Injury}

The main target damage in case of indirect ('extraplumonary') injury such as that observed in sepsis or pancreatitis is the pulmonary endothelium. Our understanding of the mechanisms that govern the pathophysiological responses of endothelial cells in ARDS remains incomplete. Several studies provide evidence that endothelial injury increases vascular permeability and thus promotes the formation of pulmonary edema, a key feature of ARDS (fig. 2). Endothelial cell function in ALI, however, may also be altered independently of any cellular damage, a phenomenon termed 'endothelial activation'. Initially, endothelial activation was defined as an increased de novo protein synthesis in response to endothelial cell stimulation. However, the recent definition additionally includes changes in the cellular phenotype such as modification of sur- face receptors in response to challenge with microbial products, cytokines, oxidants, or microcirculatory stress. The activated endothelium has a major impact on leukocyte recruitment and migration into the interstitium, and ultimately the alveolar space, by expression of adhesion and signaling molecules which facilitate leukocyte adherence. Local and systemic generation of mediators as TNF- $\alpha$ [17], IL-1 [18], reactive oxygen species [19], nitric oxide (NO) [20], and proteases may be the result and further cause of perpetuating injury [21]. Once activated, leukocytes migrate from the vascular to the alveolar compartment, where they might accumulate and initiate or amplify lung injury by release of inflammatory mediators. Another key feature of endothelial activation is the induction of local coagulation and abolished fibrinolysis, resulting in excessive fibrin deposition. Finally, activated endothelial cells can 
affect capillary fluid flux in the lung by mediators including protein kinase $\mathrm{C}$ which is known to promote barrier dysfunction [22]. Impaired balance of vasodilatory and vasoconstrictive mediators may also contribute to the microcirculatory dysfunction and subsequent poor ventilation-perfusion matching observed in ARDS.

\section{Neutrophil-Mediated Lung Injury}

Neutrophils are regarded as the main players in inflammatory processes associated with ALI/ARDS. Analysis of both histological specimens and bronchoalveolar lavage (BAL) fluid obtained from the lungs of patients with ARDS provide circumstantial evidence of marked accumulation of neutrophils in this disease [23]. In addition, several animal studies demonstrate an impressive correlation between the degree of lung injury and the influx of neutrophils into the air spaces. At the site of action, neutrophils are not only able to fight invading microorganisms but can also cause cell damage by the production and secretion of proinflammatory mediators, free radicals, reactive oxygen species, and proteases. These findings support the notion that neutrophil-dependant inflammation is not only the result but also the cause of ALI. However, there is also evidence for a neutrophil-independent mechanism since patients with profound neutropenia are able to develop ALI and ARDS [24]. In summary, it is now widely accepted that neutrophils are an important but not essential component of the injurious response.

\section{Inflammatory Mediators}

The inflammatory process in ARDS is essentially driven and amplified by a complex network of cytokines and other proinflammatory mediators, which are predominantly produced locally in the lung by neutrophils, macrophages, alveolar epithelial cells, or fibroblasts. Upon distinct stimuli, alveolar macrophages in particular secrete a plethora of proinflammatory compounds including TNF- $\alpha$, IL-1, IL-6, and IL- 8 , which by themselves act locally to stimulate chemotaxis to recruit and activate neutrophils. Many other inflammatory mediators such as high mobility group-1 protein, vascular endothelial growth factor (VEGF), or thrombin are involved in increased vascular permeability contributing to lung edema formation [25]. There is furthermore good evidence that the platelet activating factor (PAF) has significant impact on the activation of neutrophils and platelets, and that PAF application could mimic the clinical picture of ALI.

\section{Ventilator-Induced Lung Injury}

Both experimental and clinical evidence indicate that mechanical ventilation at high volumes and pressures can severely injure the lung independently of common inflammatory or toxic causes $[26,27]$. This mechanical stress might exert deleterious effects on alveolar structure and compartmentalization of the lung. Recent observations suggest that high pressure and volume ventilation induces alveolar overdistention, increased oxygen toxicity, and a possible exacerbation of inflammation as mediators or endotoxin might translocate from the lung into the systemic circulation due to a loss of pulmonary compartmentalization $[16,28]$. The combination of alveolar overdistention coupled with cyclic collapse and reopening of atelectatic alveoli is regarded as extremely harmful to lung architecture and lung function. Furthermore, the role of stretchinduced cytokine release and signal transduction is thus far poorly understood. Experimental and clinical observation of injurious ventilatory strategies has initiated the approach of lung-protective ventilation which has emerged as a key feature of ARDS treatment.

\section{Histopathology}

ALI/ARDS can be divided into 3 histopathological phases. In spite of the distinct histological characteristics of each phase, there is significant overlap which is clinically indistinguishable.

\section{Exudative Phase}

This stage occurs in the acute early phase (1-7 days after injury) and is characterized by diffuse alveolar damage (DAD) with widespread epithelial injury (particularly necrosis of alveolar type I cells) with increased alveolar-capillary permeability resulting in the accumulation of an interstitial and alveolar protein-rich edema, hemorrhage, and diffuse neutrophilic alveolar infiltrates [29]. The hallmark of this acute phase is the formation of hyaline membranes which are homogenous eosinophilic structures usually containing fibrin, immunoglobulins, debris from sloughed cells, and complement.

\section{Proliferative Phase}

The proliferative phase starts typically $1-2$ weeks after the original insult and can be regarded as a process of lung repair manifested especially as proliferation and hyperplasia of alveolar type II cells. These cells proliferate in an attempt to cover the denuded epithelial surfaces occurring after necrosis of alveolar type I cells in the early phase of ALI [25]. A second key feature is the proliferation of fibroblasts - initially only in the interstitium and later focally within the alveolar lumen - in an effort to organize DAD. The consequence of such a process is an extreme narrowing, and even obliteration, of the airways.

\section{Fibrotic Phase}

Only some patients with ALI enter this phase, typically starting 10-14 days after initial injury. It is characterized by chronic inflammation with accumulation of lymphocytes and macrophages, as well as fibrosis, and tortuous vessels narrowed by myointimal thickening and mural fibrosis. A hallmark of this phase is the dramatic and unpredictable increase in total lung collagen content resulting in reduction of lung compliance, tidal volume, and $\mathrm{CO}_{2}$ retention. Survivors of ARDS manage to eliminate this extended collagen deposition and return to relatively normal lung function, but the exact 
underlying mechanism remains a mystery [30]. Nevertheless, it has been repeatedly shown that high levels of procollagen peptides detected in early stages of ARDS and the degree of fibrosis per se can be regarded as a key predictor of poor clinical outcome.

Except in cases of lethal outcome or rapidly-progressing fibrosis, strategies for resolution of ARDS have developed. A key mechanism to resolve the alveolar edema is the active transport of sodium from the alveolar space to the interstitium, which has the consequence that edema fluid follows passively, likely through special water channels, the so-called aquaporins. As the edema in ARDS is usually protein-rich, and a framework of hyaline membranes is present throughout lung, it is problematic to remove these considerable quantities of soluble and insoluble proteins from the alveolar space. Soluble proteins are probably removed by paracellular diffusion, whereas insoluble protein is cleared by macrophages (via phagocytosis) or endocytosis by alveolar epithelial cells. As described above, alveolar type II cells initiate and promote reepithelialization of the denuded alveolar epithelium by proliferation and subsequent differentiation into type I cells. In addition, apoptosis is regarded as an essential mechanism for the clearance of neutrophils from the injured lung, however, the balance of pro- and antiapoptotic mediators in alveolar injury and repair requires further research in the future.

\section{Treatment}

\section{Mechanical Ventilation}

Mechanical ventilation is an essential component of ARDS treatment - an optimal ventilation strategy has become one of the most controversial issues in the management of ALI/ ARDS since the syndrome was firstly described. Historically, the primary goal was to achieve almost normal arterial blood gases even if high tidal volumes were required. This traditional approach led initially to an oxygenation benefit, but severe complications of this high tidal volume ventilation became rapidly evident. Animal studies indicate that alveolar overdistention by large tidal volumes can not only perpetuate but also cause lung injury [26]. This notion was supported by observations of exacerbated inflammation, destruction of alveolar architecture, and increased incidence of barotrauma, which compromise alveolar integrity and produce additional capillary leakage. These facts gave rise to the idea that tidal volumes should be reduced in the sense of a lung-protective ventilation [31]. After several animal studies and small randomized trials suggested a potential benefit of smaller tidal volumes, the NIH ARDS Network compared in a large multiple-center trial (861 patients) traditional tidal volumes (12 $\mathrm{ml} / \mathrm{kg}$ of predicted body weight) with a lower tidal volume ( $6 \mathrm{ml} / \mathrm{kg}$ of predicted body weight). This study demonstrated a significant reduction in 28-day mortality from 40 to $31 \%$ in the group with low tidal volume and a plateau pressure of
$30 \mathrm{~cm}$ of $\mathrm{H}_{2} \mathrm{O}$ [13]. Although this study has generated substantial debate, low-tidal volume lung-protective ventilation is the only intervention which proved to reduce mortality and therefore should be nowadays standard of care in the management of ALI and ARDS [32]. To further optimize ARDS ventilation strategies there has also been considerable interest in the identification of optimal level of positive end-expiratory pressure (PEEP) in these patients. A higher level of PEEP ('open lung concept') might improve oxygenation mostly by stabilizing injured and recruiting collapsed alveoli but showed often increased adverse effects like a decrease of cardiac output, overdistention of already recruited alveoli with subsequent barotraumas or increased lung edema formation. The ARDS Network conducted a multiple-center randomized trial to investigate the effect of PEEP on survival, but no PEEP concept proved to be superior in terms of clinical outcome [33]. A moderate level of PEEP in combination with a lung-protective ventilation currently seems to be the best available approach to ventilate patients with the ARDS [32].

\section{Fluid Management}

Optimal fluid management in ALI/ARDS is one of the most controversial issues in disease management currently discussed. The rationale for restricting fluids in ARDS patients is to lower vascular filling pressure and thereby reduce pulmonary edema. Observational studies with ARDS patients who had a negative fluid balance demonstrated improved survival [34-36]. The second concept, favoring a higher volume status, prioritizes cardiac output, organ perfusion, and oxygen delivery. The ARDS Network compared these 2 fluid management strategies in ALI, described an improved oxygenation index, and shortened duration of mechanical ventilation in the group of patients receiving a conservative, restrictive fluid therapy [37]. Despite such advantages, a significant difference in mortality could not be observed. Despite a paucity of studies, it is a reasonable objective to maintain the intravascular volume at the lowest level that is consistent with adequate systemic perfusion especially when treating septic patients with ARDS.

\section{Surfactant Therapy}

Decreased surfactant function due to reduced production by injured alveolar type II cells and inhibition by extravasated fibrin is a key feature of ARDS. Surfactant replacement therapy has been shown to be successful in infants with neonatal respiratory distress syndrome [38]. Therefore, treatment with surfactant has also been proposed in ALI/ARDS patients to compensate possible formation of atelectasis and thus improve oxygenation. Although several preliminary phase I and II studies yielded encouraging results concerning pulmonary function and mortality, a recent multiple-center, randomized, controlled phase III trial in 448 patients with intratracheal installation of SP-C-based surfactant failed to demonstrate changes in the duration of mechanical ventilation or in sur- 
vival [39]. Currently, there is no evidence that surfactant therapy improves the mortality observed in ARDS patients. However, clinical trials are underway investigating different surfactant preparations and the subgroups within the patient population under study.

\section{Glucocorticoids}

Due to their anti-inflammatory and anti-fibrotic properties, glucocorticosteroids were the earliest therapeutic option evaluated for the treatment of both the early exudative, as well as the late proliferative phase of ARDS. Glucocorticoids can effectively reduce the inflammatory reaction by inhibiting the production of proinflammatory cytokines such as TNF- $\alpha$, IL-1, IL-6, and IL-8. In addition, glucocorticoids play a pivotal role in collagen degradation, and might prevent excessive deposition of extracellular matrix. Early studies conducted in the 1980s in ARDS patients failed to demonstrate any benefit of short-term, high-dose methylprednisolone treatment to prevent the development of ARDS or to reduce mortality when administered in the early phase of this syndrome [40, 41]. Despite the failure of the randomized trials concerning prevention or early treatment, great interest remained using glucocorticoids to treat the late fibrosing phase of the disease. Several small uncontrolled studies and case reports suggested a clinical benefit of extended therapy with moderate to highdose glucocorticoids concerning mortality and lung injury score $[42,43]$. Encouraging results in these studies stimulated the ARDS Network to undertake a large multiple-center randomized controlled trial, called the Late Steroid Rescue Study. The results do not support the routine use of glucocorticoids for persistent ARDS as no difference in 60-day or 180-day mortality could be shown, despite the observed improvements in gas exchange and time on ventilation [44]. In a recent study, Meduri et al. [45] investigated in a randomized, controlled trial the effect of low-dose prolonged administration of methylprednisolone in early ARDS. Low-dose glucocorticoid treatment was associated with a reduction of lung injury score and need for ventilation as primary endpoints. In addition, a reduction in ICU mortality and infections were reported. In conclusion, there is not enough evidence to support the routine use of glucocorticoids in the early and late phase of ALI/ ARDS. However, recent data indicate a survival benefit of low-dose glucocorticoid treatment in early ARDS, which will need confirmation in a larger trial.

\section{Inhaled Vasodilators}

One key pathophysiological characteristic of ARDS is the loss of hypoxic vasoconstriction in the non-ventilated lung regions and impaired vasodilatation in aerated pulmonary regions, resulting in increased intra-pulmonary right-to-left shunting, dead-space ventilation, elevated pulmonary artery pressures, and severe hypoxemia. Therapeutic use of selective pulmonary vasodilators could address this mechanism by improv- ing the ventilation-perfusion matching and decreasing pulmonary artery pressure resulting in an improvement of oxygenation. Based on these ideas, 2 selective pulmonary vasodilators, inhaled NO and inhaled prostacyclins, have been tested for the treatment of ALI/ARDS patients. Due to its physiological properties, NO seemed to be an ideal therapeutic agent for selective intra-pulmonary vasodilatation in ARDS. On the basis of promising results in animal models, Rossaint et al. [46] published data demonstrating that NO inhalation caused a significant improvement in arterial oxygenation and reduction of pulmonary artery pressure. To translate these encouraging physiological effects into improved clinical outcome, several randomized, controlled studies were conducted $[47,48]$. Despite beneficial effects on oxygenation and ventilation-to-perfusion ratio, a survival benefit with inhaled NO was not detected. Walmrath et al. [49] were the first to demonstrate that inhaled prostacyclins, such as aerosolized prostaglandin $I_{2}$, possess selective vasodilatory properties in severe ARDS. Several subsequent observational studies confirmed an improvement in oxygenation, ventilation dependency, or lung compliance, but no difference in mortality [50,51]. In summary, existing data suggest that the routine use of inhaled NO and prostacyclins cannot be recommended in ALI/ARDS treatment, whereas they might be useful as a rescue therapeutic option for severe ARDS with refractory hypoxemia.

\section{Extra-Corporal Membrane Oxygenation}

Extra-corporal membrane oxygenation (ECMO) is designed to establish an extra-corporal circuit to improve oxygenation in patients refractory to conventional ventilatory support. Although some studies have revealed beneficial effects and the use of ECMO technology is widely accepted in pediatric intensive care medicine, controlled clinical trials did not reveal an improvement in survival or ventilation time [52, 53]. For this reason, ECMO therapy cannot be recommended for routine management in ALI/ARDS but might be useful as a rescue option in cases with refractory hypoxemia.

\section{Supportive Care}

The reported decline in mortality in patients with ARDS over the past decades is closely associated with advances in supportive care. General principles of this supportive care include the early identification and subsequent aggressive treatment of the underlying causes of ALI/ARDS. Furthermore, potential complications such as secondary infections, gastrointestinal ulcers and bleeding, and thromboembolism should be minimized. Another essential component of appropriate supportive care is the supply of adequate nutrition to ARDS patients to optimize the metabolic rate. A very promising attempt is the administration of fish oil-enriched nutrition that improved oxygenation and ventilation time in several trials including a multiple-center randomized controlled study [54-57]. 


\section{Conclusion}

Since the first description of ARDS in 1967, there has been tremendous progress in the understanding of this syndrome and its therapy, which is reflected in constantly declining mortality rated from $60 \%$ in the early years to about $30-40 \%$ at present. Despite encouraging results in pharmacotherapy, only low-tidal volume lung-protective ventilation has proven to have a significant mortality benefit for ARDS patients. Although preliminary studies often demonstrate promising results, all pharmacological interventions attempted to date have failed to reduce the mortality rate in ARDS patients, and can currently not be recommended for use in standard therapy.

What might be the reason for the lack of success of pharmacotherapy in the treatment of ALI/ARDS? As mentioned earlier, the pathophysiology of ARDS can be divided into several distinct phases, differing in histological features, physiology, and pathology. It might be assumed that the early and late phase of ARDS might require different pharmacological approaches. As the heterogeneity of ARDS patients makes it difficult to identify a universal pharmacological therapy, special attention should be paid to an appropriate patient selection for clinical trials. Effective future therapeutic approaches for ARDS treatment may also include the emerging areas of basic research as stem cell- or gene therapy-based approaches.

\section{Acknowledgement}

The study was supported by the Deutsche Forschungsgesellschaft (DFG), Collaborative Research Centre 547 'Cardio-pulmonary vascular system', project B4; Excellence Cluster Cardiopulmonary System ECCPS, DFG; and Forschungsförderung gemäß Kooperationsvertrag Rhön-Klinikum

\section{References}

$\checkmark 1$ Ashbaugh DG, Bigelow DB, Petty TL, Levine BE: Acute respiratory distress in adults. Lancet 1967;2: 319-323.

-2 Bernard GR, Artigas A, Brigham KL, Carlet J, Falke K, Hudson L, Lamy M, Legall JR, Morris A Spragg R: The American-European Consensus Conference on ARDS. Definitions, mechanisms, relevant outcomes, and clinical trial coordination. Am J Respir Crit Care Med 1994;149:818-824.

$\checkmark 3$ Rocco PR, Zin WA: Pulmonary and extrapulmonary acute respiratory distress syndrome: are they different? Curr Opin Crit Care 2005;11:10-17.

4 Wind J, Versteegt J, Twisk J, van der Werf TS, Bindels AJ, Spijkstra JJ, Girbes AR, Groeneveld AB: Epidemiology of acute lung injury and acute respiratory distress syndrome in The Netherlands: a survey. Respir Med 2007;101:2091-2098.

5 Reynolds HN, McCunn M, Borg U, Habashi N, Cottingham $\mathrm{C}$, Bar-Lavi Y: Acute respiratory distress syndrome: estimated incidence and mortality rate in a 5 million-person population base. Crit Care 1998;2:29-34

6 Rubenfeld GD, Caldwell E, Peabody E, Weaver J, Martin DP, Neff M, Stern EJ, Hudson LD: Incidence and outcomes of acute lung injury. N Engl J Med 2005;353:1685-1693.

7 Goss CH, Brower RG, Hudson LD, Rubenfeld GD: Incidence of acute lung injury in the United States. Crit Care Med 2003;31:1607-1611.

8 Bersten AD, Edibam C, Hunt T, Moran J: Incidence and mortality of acute lung injury and the acute respiratory distress syndrome in three Australian States. Am J Respir Crit Care Med 2002;165: 443-448.

$\checkmark 9$ Arroliga AC, Ghamra ZW, Perez Trepichio A, Perez Trepichio P, Komara JJ Jr, Smith A, Wiedemann HP: Incidence of ARDS in an adult population of northeast Ohio. Chest 2002;121:1972-1976.

10 Brun-Buisson C, Minelli C, Bertolini G, Brazzi L, Pimentel J, Lewandowski K, Bion J, Romand JA, Villar J, Thorsteinsson A, Damas P, Armaganidis A Lemaire F: Epidemiology and outcome of acute lung injury in European intensive care units. Results from the ALIVE study. Intensive Care Med 2004:30:51-61.
11 Esteban A, Anzueto A, Frutos F, Alia I, Brochard L, Stewart TE, Benito S, Epstein SK, Apezteguia C, Nightingale P, Arroliga AC, Tobin MJ: Characteristics and outcomes in adult patients receiving mechanical ventilation: a 28-day international study. Jama 2002;287:345-355.

12 Wheeler AP, Bernard GR: Acute lung injury and the acute respiratory distress syndrome: a clinical review. Lancet 2007;369:1553-1564.

13 Ventilation with lower tidal volumes as compared with traditional tidal volumes for acute lung injury and the acute respiratory distress syndrome. The Acute Respiratory Distress Syndrome Network. N Engl J Med 2000;342:1301-1308.

14 Atabai K, Matthay MA: The pulmonary physician in critical care. 5: Acute lung injury and the acute respiratory distress syndrome: definitions and epidemiology. Thorax 2002;57:452-458.

15 Fowler AA, Hamman RF, Good JT, Benson KN, Baird M, Eberle DJ, Petty TL, Hyers TM: Adult respiratory distress syndrome: risk with common predispositions. Ann Intern Med 1983;98:593-597.

16 Ware LB, Matthay MA: The acute respiratory distress syndrome. N Engl J Med 2000;342:1334-1349.

17 Stephens KE, Ishizaka A, Larrick JW, Raffin TA: Tumor necrosis factor causes increased pulmonary permeability and edema. Comparison to septic acute lung injury. Am Rev Respir Dis 1988;137: 1364-1370.

18 Hassoun PM, Yu FS, Cote CG, Zulueta JJ, Sawhney R, Skinner KA, Skinner HB, Parks DA, Lanzillo JJ: Upregulation of xanthine oxidase by lipopolysaccharide, interleukin-1, and hypoxia. Role in acute lung injury. Am J Respir Crit Care Med 1998;158: 299-305.

19 Wang W, Suzuki Y, Tanigaki T, Rank DR, Raffin TA: Effect of the NADPH oxidase inhibitor apocynin on septic lung injury in guinea pigs. Am J Respir Crit Care Med 1994;150:1449-1452.

20 Wizemann TM, Gardner CR, Laskin JD, Quinones S, Durham SK, Goller NL, Ohnishi ST, Laskin DL: Production of nitric oxide and peroxynitrite in the lung during acute endotoxemia. J Leukoc Biol 1994;56:759-768.
21 Seeger W, Obernitz R, Thomas M, Walmrath D, Suttorn N, Holland IB, Grimminger F, Eberspacher B, Hugo F, Bhakdi S: Lung vascular injury after administration of viable hemolysin-forming Escherichia coli in isolated rabbit lungs. Am Rev Respir Dis 1991;143:797-805.

22 Siflinger-Birnboim A, Johnson A: Protein kinase C modulates pulmonary endothelial permeability: a paradigm for acute lung injury. Am J Physiol Lung Cell Mol Physiol 2003;284:L435-451.

23 Pittet JF, Mackersie RC, Martin TR, Matthay MA: Biological markers of acute lung injury: prognostic and pathogenetic significance. Am J Respir Crit Care Med 1997;155:1187-1205.

24 Laufe MD, Simon RH, Flint A, Keller JB: Adult respiratory distress syndrome in neutropenic patients. Am J Med 1986;80:1022-1026.

25 Bellingan GJ: The pulmonary physician in critical care * 6: The pathogenesis of ALI/ARDS. Thorax 2002;57:540-546.

26 Webb HH, Tierney DF: Experimental pulmonary edema due to intermittent positive pressure ventilation with high inflation pressures. Protection by positive end-expiratory pressure. Am Rev Respir Dis 1974;110:556-565.

27 Dreyfuss D, Soler P, Basset G, Saumon G: High inflation pressure pulmonary edema. Respective effects of high airway pressure, high tidal volume, and positive end-expiratory pressure. Am Rev Respir Dis 1988:137:1159-1164.

28 Parker JC, Townsley MI, Rippe B, Taylor AE, Thigpen J: Increased microvascular permeability in dog lungs due to high peak airway pressures. J Appl Physiol 1984;57:1809-1816.

29 Tomashefski JF Jr: Pulmonary pathology of the adult respiratory distress syndrome. Clin Chest Med 1990;11:593-619.

30 McHugh LG, Milberg JA, Whitcomb ME, Schoene RB, Maunder RJ, Hudson LD: Recovery of function in survivors of the acute respiratory distress syndrome. Am J Respir Crit Care Med 1994;150: 90-94.

31 Brower RG, Ware LB, Berthiaume Y, Matthay MA: Treatment of ARDS. Chest 2001;120:1347-1367.

32 Malhotra A: Low-tidal-volume ventilation in the acute respiratory distress syndrome. N Engl J Med 2007;357:1113-1120. 
33 Brower RG, Lanken PN, MacIntyre N, Matthay MA, Morris A, Ancukiewicz M, Schoenfeld D, Thompson BT: Higher versus lower positive endexpiratory pressures in patients with the acute respiratory distress syndrome. N Engl J Med 2004;351: 327-336.

-34 Sakr Y, Vincent JL, Reinhart K, Groeneveld J, Michalopoulos A, Sprung CL, Artigas A, Ranieri VM: High tidal volume and positive fluid balance are associated with worse outcome in acute lung injury. Chest 2005;128:3098-3108.

- 35 Simmons RS, Berdine GG, Seidenfeld JJ, Prihoda TJ, Harris GD, Smith JD, Gilbert TJ, Mota E, Johanson WG Jr: Fluid balance and the adult respiratory distress syndrome. Am Rev Respir Dis 1987; 135:924-929.

36 Humphrey H, Hall J, Sznajder I, Silverstein M, Wood L: Improved survival in ARDS patients associated with a reduction in pulmonary capillary wedge pressure. Chest 1990;97:1176-1180.

37 Wiedemann HP, Wheeler AP, Bernard GR, Thompson BT, Hayden D, deBoisblanc B, Connors AF Jr, Hite RD, Harabin AL: Comparison of two fluidmanagement strategies in acute lung injury. N Engl J Med 2006;354:2564-2575.

38 Cepkova M, Matthay MA: Pharmacotherapy of acute lung injury and the acute respiratory distress syndrome. J Intensive Care Med 2006;21:119-143.

-39 Spragg RG, Lewis JF, Walmrath HD, Johannigman J, Bellingan G, Laterre PF, Witte MC, Richards GA Rippin G, Rathgeb F, Hafner D, Taut FJ, Seeger W: Effect of recombinant surfactant protein C-based surfactant on the acute respiratory distress syndrome. N Engl J Med 2004;351:884-892.

40 Weigelt JA, Norcross JF, Borman KR, Snyder WH 3rd: Early steroid therapy for respiratory failure. Arch Surg 1985;120:536-540.

41 Sprung CL, Caralis PV, Marcial EH, Pierce M, Gelbard MA, Long WM, Duncan RC, Tendler MD, Karpf M: The effects of high-dose corticosteroids in patients with septic shock. A prospective, controlled study. N Engl J Med 1984;311:1137-1143.
42 Hooper RG, Kearl RA: Established ARDS treated with a sustained course of adrenocortical steroids. Chest 1990;97:138-143.

43 Meduri GU, Belenchia JM, Estes RJ, Wunderink RG, el Torky M, Leeper KV Jr: Fibroproliferative phase of ARDS. Clinical findings and effects of corticosteroids. Chest 1991;100:943-952.

44 Steinberg KP, Hudson LD, Goodman RB, Hough CL, Lanken PN, Hyzy R, Thompson BT, Ancukiewicz M: Efficacy and safety of corticosteroids for persistent acute respiratory distress syndrome. N Engl J Med 2006;354:1671-1684.

45 Meduri GU, Golden E, Freire AX, Taylor E, Zaman M, Carson SJ, Gibson M, Umberger R: Methylprednisolone infusion in early severe ARDS: results of a randomized controlled trial. Chest 2007;131:954-963.

46 Rossaint R, Falke KJ, Lopez F, Slama K, Pison U, Zapol WM: Inhaled nitric oxide for the adult respiratory distress syndrome. N Engl J Med 1993;328: 399-405.

47 Michael JR, Barton RG, Saffle JR, Mone M, Markewitz BA, Hillier K, Elstad MR, Campbell EJ, Troyer BE, Whatley RE, Liou TG, Samuelson WM, Carveth HJ, Hinson DM, Morris SE, Davis BL, Day RW: Inhaled nitric oxide versus conventional therapy: effect on oxygenation in ARDS. Am J Respir Crit Care Med 1998;157:1372-1380.

48 Dellinger RP, Zimmerman JL, Taylor RW, Straube RC, Hauser DL, Criner GJ, Davis K Jr, Hyers TM, Papadakos P: Effects of inhaled nitric oxide in patients with acute respiratory distress syndrome: results of a randomized phase II trial. Inhaled Nitric Oxide in ARDS Study Group. Crit Care Med 1998; 26:15-23.

49 Walmrath D, Schneider T, Pilch J, Grimminger F, Seeger W: Aerosolised prostacyclin in adult respiratory distress syndrome. Lancet 1993;342:961-962.

50 Abraham E, Park YC, Covington P, Conrad SA, Schwartz M: Liposomal prostaglandin E1 in acute respiratory distress syndrome: a placebo-controlled, randomized, double-blind, multicenter clinical trial. Crit Care Med 1996;24:10-15.
51 Abraham E, Baughman R, Fletcher E, Heard S, Lamberti J, Levy H, Nelson L, Rumbak M, Steingrub J, Taylor J, Park YC, Hynds JM, Freitag J: Liposomal prostaglandin E1 (TLC C-53) in acute respiratory distress syndrome: a controlled, randomized, double-blind, multicenter clinical trial. TLC C-53 ARDS Study Group. Crit Care Med 1999;27: 1478-1485.

52 Zapol WM, Snider MT, Hill JD, Fallat RJ, Bartlett RH, Edmunds LH, Morris AH, Peirce EC 2nd, Thomas AN, Proctor HJ, Drinker PA, Pratt PC, Bagniewski A, Miller RG Jr: Extracorporeal membrane oxygenation in severe acute respiratory failure. A randomized prospective study. Jama 1979; 242:2193-2196.

53 Gattinoni L, Presenti A, Torresin A, Baglioni S, Rivolta M, Rossi F, Scarani F, Marcolin R, Cappelletti G: Adult respiratory distress syndrome profiles by computed tomography. J Thorac Imaging 1986;1: 25-30.

54 Gadek JE, DeMichele SJ, Karlstad MD, Pacht ER, Donahoe M, Albertson TE, Van Hoozen C, Wennberg AK, Nelson JL, Noursalehi M: Effect of enteral feeding with eicosapentaenoic acid, gammalinolenic acid, and antioxidants in patients with acute respiratory distress syndrome. Enteral Nutrition in ARDS Study Group. Crit Care Med 1999; 27:1409-1420.

55 Singer P, Theilla M, Fisher H, Gibstein L, Grozovski E, Cohen J: Benefit of an enteral diet enriched with eicosapentaenoic acid and gamma-linolenic acid in ventilated patients with acute lung injury. Crit Care Med 2006:34:1033-1038.

56 Pontes-Arruda A, Aragao AM, Albuquerque JD: Effects of enteral feeding with eicosapentaenoic acid, gamma-linolenic acid, and antioxidants in mechanically ventilated patients with severe sepsis and septic shock. Crit Care Med 2006;34:2325-2333.

57 Mayer K, Schaefer MB, Seeger W: Fish oil in the critically ill: from experimental to clinical data. Curr Opin Clin Nutr Metab Care 2006;9:140-148. 